1 Fundação Oswaldo Cruz (Fiocruz), Escola Nacional de Saúde Pública Sergio Arouca (Ensp) - Rio de Janeiro (RJ), Brasil. julmatos@gmail.com

\section{Expressões da precarização do trabalho nas regras do jogo: Organizações Sociais na Atenção Primária do município do Rio}

\author{
Expressions of precarious working conditions in the rules of the game: \\ Social Organizations in Primary Care in the municipality of Rio
}

Júlia Matos da Fonseca', Sheyla Maria Lemos Lima', Marcia Teixeira'

\begin{abstract}
RESUMO Objetivou-se analisar as relações de trabalho no âmbito da Atenção Primária (AP) operada pelas Organizações Sociais (OSs) no município do Rio de Janeiro no período de 2009 a 2019. Foram utilizadas contribuições do neoinstitucionalismo histórico para analisar as regras formais das relações de trabalho e sua relação com a precarização a partir dos documentos elaborados pelas instâncias legislativa, executiva e prestadora de serviços. Foram consideradas as modalidades de contratação; contribuições previdenciárias ou trabalhistas; modalidades de recrutamento e seleção; representação dos trabalhadores; plano de cargos, salários e benefícios; remuneração; escopo de práticas e composição das equipes. Destacaram-se como expressões da precarização as incertezas na garantia de direitos trabalhistas, a insegurança quanto ao futuro profissional, a sobrecarga de trabalho, entre outros. O estudo da trajetória da política de AP no período considerado permitiu reconstruir argumentos, dimensões legislativas e regulamentares, bem como as inflexões e a evolução da política. As regras do jogo contidas nas normativas expressam a flexibilização e a precarização do trabalho na AP do município, colocando em questão a sustentabilidade dos serviços baseados no modelo das OSs.
\end{abstract}

PALAVRAS-CHAVE Trabalho. Organização Social. Atenção Primária à Saúde.

\begin{abstract}
The objective was to analyze the labor relations in the scope of Primary Care operated by Social Organizations in the city of Rio de Janeiro in the period from 2009 to 2019. The contributions of historical neoinstitutionalism were used to analyze the formal rules of labor relations and their relationship with precarious working conditions based on documents prepared by the legislative, executive and service providers. The following hiring modalities were considered: social security or labor contributions; recruitment and selection modalities; worker representation; job, salary and benefits plan; remuneration; scope of practices and team composition. The uncertainties in guaranteeing labor rights, insecurity about the professional future, work overload, among others, stood out as expressions of precarious working conditions. The study of the trajectory of Primary Care policy in the considered period reconstructs arguments, legislative and regulatory dimensions, as well as the inflections and evolution of the policy. The rules of the game contained in the regulations express the flexibility and precarious working conditions in Primary Care in the municipality, calling into question the sustainability of services based on the model of Social Organizations.
\end{abstract}




\section{Introdução}

A precarização, conceito abrangente para a compreensão das relações de trabalho, tem sido utilizada para se referir a uma piora das condições de trabalho, seja pela diminuição dos postos, redução dos direitos e incremento do trabalho informal, temporário, intermitente, entre outros' ${ }^{1}$. O trabalho precário se caracteriza pela incerteza e imprevisibilidade, no qual os riscos empregatícios passam a ser assumidos principalmente pelos trabalhadores, e não mais pelos empregadores ${ }^{2}$.

No campo da precarização, inserem-se, ainda, a flexibilização, compreendida como um conjunto de medidas para adaptar ou eliminar direitos trabalhistas de acordo com a realidade econômica e produtiva, e a terceirização, conceituada como a transferência de parte do processo produtivo de uma organização (contratante) para outra (contratada ou 'terceirizada') ${ }^{3,4}$. A terceirização pode se manifestar como quarteirização, quando há uma intermediadora responsável por gerenciar contratos entre a 'empresa-mãe' e a empresa terceirizada, e/ou quando a empresa terceirizada contratada pela 'empresa-mãe' repassa as atividades a serem realizadas para outras empresas, cooperativas de trabalho (trabalhadores 'autônomos') ou prestadores de serviços individuais (Pessoas Jurídicas - PJ) ${ }^{\mathbf{5}}$. Portanto, a terceirização e seus desdobramentos, ao permitirem condições de trabalho e de proteção social inferiores, vinculam-se à precarização do trabalho ${ }^{6}$.

Nos últimos anos, as relações de trabalho mais estáveis e com vínculos formais têm sido substituídas por relações mais flexíveis, diminuindo o acesso a direitos trabalhistas e acarretando aumento da precarização das relações de trabalho. Esse cenário se relaciona com a situação macroeconômica e, portanto, com a política econômica do neoliberalismo ${ }^{7}$.

Com o avanço do neoliberalismo, diversos países realizaram reformas administrativas, políticas e econômicas ${ }^{\mathbf{8} 9}$. Nesse contexto, ocorreram mudanças no modelo de gestão das instituições do Estado que foram influenciadas por uma agenda pautada na Nova Gestão Pública. Esse modelo introduziu arranjos alternativos à gestão direta do Estado, mais próximos àqueles praticados no setor privado, gerando mudanças nos processos de trabalho dos serviços públicos, inclusive na saúde ${ }^{9,10}$.

No Brasil, esse debate ganhou concretude com a criação, em 1995, do Ministério da Administração e Reforma do Estado e com a elaboração do Plano Diretor da Reforma do Aparelho do Estado 8 . Foi criado um novo ente jurídico administrativo, as Organizações Sociais (OSs) (Lei no 9.637/1998), qualificação concedida a entidades já existentes, de direito privado e sem fins lucrativos, que realizariam parceria com o Estado intermediadas por um contrato de gestão"11. Assim, o Plano Diretor, a lei de qualificação e os contratos de gestão expressam marcos regulatórios que permitiram a adoção do modelo das OSs.

Mais recentemente, mudanças nos regramentos institucionais tiveram efeitos nas relações de trabalho do País. Desde 2016, iniciou-se um processo de revisão de políticas sociais de forma mais intensa, a partir do aprofundamento das políticas de austeridade, com a aprovação de um conjunto de reformas. Tais reformas são denominadas contrarreformas, ressaltando o retrocesso que provocaram na regulação social do trabalho ${ }^{\mathbf{1 2}, 13}$.

Uma delas foi a Emenda Constitucional $\mathrm{n}^{\mathrm{o}}$ 95 (EC 95), de 2016, que congelou despesas primárias do setor público por vinte anos, sendo atualizadas apenas pela inflação do ano anterior com base na variação do Índice de Preços ao Consumidor Amplo (IPCA) ${ }^{\mathbf{1 4}}$. Nesse sentido, a EC 95 intensificou o subfinanciamento do Sistema Único de Saúde (SUS), acarretando restrições financeiras aos municípios com reflexos na contratação e remuneração dos trabalhadores.

A reforma trabalhista, aprovada com a Lei $\mathrm{n}^{\circ} 13.467$, de 2017, alterou diversos pontos da Consolidação das Leis Trabalhistas (CLT), como, por exemplo, a contribuição sindical; o acordo entre as partes para demissão sem justa 
causa; o contrato de trabalho intermitente; horas extras, entre outros ${ }^{15}$. Adicionalmente, a lei da terceirização (Lei n ${ }^{\circ} 13.429 / 2017$ ) passou a permitir a terceirização das atividades-fimm ${ }^{16}$.

Diante das mudanças na regulação do trabalho, este artigo tem como objetivo analisar as relações de trabalho no âmbito da Atenção Primária (AP) operada pelas OSs no município do Rio de Janeiro, no período de 2009 a 2019, a partir da análise das regras formais que sustentaram essas relações, identificando possíveis expressões de precarização.

\section{Material e métodos}

Durante o período estudado, as OSs foram responsáveis por grande parte da AP no município do Rio, sendo que, em 2015, geriam 98\% das unidades de AP17. Entre 2009 e 2019, atuaram 11 OSs diferentes: Instituto Social Fibra (Fibra); Viva Rio; Centro Integrado e Apoio Profissional (Ciap); Associação Global Soluções em Saúde (Global); Fundação para o Desenvolvimento Científico e Tecnológico em Saúde (Fiotec); Instituto Gnosis (Gnosis); Instituto de Atenção Básica e Avançada à Saúde (Iabas); Associação Paulista para o Desenvolvimento da Medicina (SPDM); Centro de Estudos e Pesquisas 28 (CEP 28), Instituto de Psicologia Clínica Educacional e Profissional (IPCEP) e Instituto de Desenvolvimento Institucional e Ação Social (Ideias) ${ }^{18}$.

Realizou-se análise documental das regras produzidas pelas instâncias legislativa, executiva e prestadora de serviços, a fim de compreender as relações de trabalho estabelecidas na AP no município do Rio. O referencial de análise utilizado foi o neoinstitucionalismo, que considera que as regras formais (leis, normas) e informais (código de conduta, hábitos) influenciam as interações humanas ${ }^{19,20}$. Assim, os documentos analisados foram considerados como regras formais que moldam as relações de trabalho estabelecidas na AP com as OSs. O neoinstitucionalismo histórico sustentou a análise da trajetória das políticas implementadas no período entre 2009 (início da contratação das OSs na AP) e 2019, compreendendo dois mandatos do governo Eduardo Paes e um do governo Marcelo Crivella.

No âmbito legislativo, foram consideradas: a Lei federal $n^{\circ} 9.637$, de 1998, a Lei municipal $n^{\circ} 5.026$, de 2009 , e o decreto municipal $n^{\circ} 30.780$, de 2009, que dispõem sobre a qualificação de entidades como Organizações Sociais 11,21,22.

Na instância executiva, foram analisados: a Política Nacional de Atenção Básica (PNAB) de 2017, referente ao âmbito federal; três Planos Municipais de Saúde (dois do governo do Eduardo Paes e um do Marcelo Crivella); o documento 'Reorganização dos Serviços de Atenção Primária à Saúde - Estudo para otimização de recursos' (governo Marcelo Crivella); o 'Relatório Parcial - $1^{\mathrm{a}}$ versão (2018)' (grupo de trabalho do Conselho Municipal de Saúde); e 27 contratos de gestão - instrumento que regula a relação entre a Secretaria Municipal de Saúde (SMS) (contratante) e a OS (contratada) - relativos às OSs atuantes no período de 2009 a 201923-28. Não foram considerados os contratos de gestão emergenciais, e, por isso, a CEP 28 e a IPCEP não foram incluídas na análise.

Na instância prestadora, foram analisados 5 estatutos - funções, atos e objetivos da instituição - referentes às OSs Fiotec, Iabas, Gnosis, SPDM e Viva Rio ${ }^{29-33}$. Não foram obtidos os estatutos das demais OSs. Sobre os regulamentos de contratação de pessoal, foram acessados os de 4 OSs: Iabas, Gnosis, SPDM e Viva Rio ${ }^{34-37}$. Cabe a observação de que a Fiotec não possui regulamento de contratação de pessoal. Quanto às demais OSs, não foram identificados em seus sites eletrônicos os regulamentos de pessoal. Foram também acessados os 206 editais completos de seleção de pessoal no período de 2009 a 2019, referentes às OSs Fibra (2), Fiotec (14), Gnosis (4), Iabas (68), IPCEP (23), SPDM (51) e Viva Rio (44). Dos editais, foram apenas considerados aspectos relevantes da precarização do trabalho.

Ao todo, foram analisados 251 documentos das três instâncias formuladoras de regras 
para a AP do município do Rio de Janeiro, deles extraindo indicadores sobre relações de trabalho apresentados no quadro 1.

O estudo não foi submetido ao Comitê de Ética em Pesquisa em função da dispensabilidade - dados de acesso público e irrestrito -, de acordo com os requisitos da Resolução no 466 , de 2012, e da Resolução ${ }^{0}$ 510, de 2016, do Conselho Nacional de Saúde.

Quadro 1. Indicadores selecionados sobre relações de trabalho - 2009/2019

\begin{tabular}{|c|c|c|}
\hline Instância & Documentos* & Indicadores \\
\hline Legislativa & $\begin{array}{l}\text { Lei federal no 9.637/1998; lei munici- } \\
\text { pal no 5.026/2009 e decreto munici- } \\
\text { pal no 30.780/2009 }\end{array}$ & $\begin{array}{l}\text { Representação de trabalhadores; plano de cargos, salários e } \\
\text { benefícios; remuneração; contribuições previdenciárias ou } \\
\text { trabalhistas; cessão de servidores; complementação salarial de } \\
\text { servidores cedidos }\end{array}$ \\
\hline \multirow[t]{4}{*}{ Executiva } & $\begin{array}{l}\text { Política nacional de atenção básica } \\
2017\end{array}$ & $\begin{array}{l}\text { Número de agente comunitário de saúde por equipe; incentivo } \\
\text { financeiro das equipes de atenção básica tradicional; escopo de } \\
\text { práticas dos agentes comunitários }\end{array}$ \\
\hline & 3 planos municipais de saúde & Equipes de saúde da família e suas modalidades de contratação \\
\hline & $\begin{array}{l}\text { Documento 'Reorganização dos } \\
\text { serviços de atenção primária à saúde } \\
\text { - estudo para otimização de recursos' } \\
\text { e o 'Relatório parcial - 1̄ versão' }\end{array}$ & $\begin{array}{l}\text { Número de trabalhadores e equipes de saúde da família; tipolo- } \\
\text { gia das equipes }\end{array}$ \\
\hline & 27 contratos de gestão & $\begin{array}{l}\text { Contratação de pessoal; remuneração; contribuições previden- } \\
\text { ciárias ou trabalhistas; reserva de vagas/cotas; cessão de ser- } \\
\text { vidores; rescisão por parte da contratante - responsabilidade } \\
\text { sobre os custos de dispensa de pessoal; controle da jornada de } \\
\text { trabalho }\end{array}$ \\
\hline \multirow[t]{3}{*}{$\begin{array}{l}\text { Prestadora } \\
\text { de servi- } \\
\text { cos/OS }\end{array}$} & 5 estatutos & $\begin{array}{l}\text { Atribuições referentes às relações de trabalho (plano de cargos, } \\
\text { salários e benefícios; política de recursos humanos/manual de } \\
\text { recursos humanos; admissão, contratação, demissão, promo- } \\
\text { ção e delegação de atribuições dos trabalhadores; formação } \\
\text { dos trabalhadores); participação de trabalhadores (participação } \\
\text { como associados; representação no conselho de administra- } \\
\text { ção); remuneração de trabalhadores associados e conselheiros } \\
\text { (remuneração de associados; remuneração de conselheiros de } \\
\text { administração) }\end{array}$ \\
\hline & $\begin{array}{l}4 \text { regulamentos de contratação de } \\
\text { pessoal }\end{array}$ & $\begin{array}{l}\text { Procedimentos de incorporação/contratação de trabalhadores } \\
\text { (modalidade de recrutamento e seleção; reserva de vagas/ } \\
\text { cotas; modalidade de contratação) e procedimentos de gestão } \\
\text { de trabalho (pagamento; benefícios; licenças; avaliação de } \\
\text { desempenho; controle da jornada de trabalho; promoção; re- } \\
\text { manejamento/transferência; extinção/rescisão do contrato de } \\
\text { trabalho) }\end{array}$ \\
\hline & 206 editais de seleção completos & $\begin{array}{l}\text { Modalidade de recrutamento e seleção; remuneração; requisi- } \\
\text { tos para concorrer à vaga }\end{array}$ \\
\hline
\end{tabular}

Fonte: Elaboração própria.

* Documentos acessados em: Site de busca Google, Site da Prefeitura do Rio de Janeiro, Sistema de legislação da saúde (Saúde Legis), Sites das Organizações Sociais de Saúde e redes sociais Facebook/Instagram. 


\section{Resultados e discussão}

Os resultados estão apresentados segundo duas grandes categorias que expressam a precarização de trabalho: contratação dos trabalhadores (modalidades de contratação; contribuições previdenciárias ou trabalhistas; modalidades de recrutamento e seleção) e gestão do trabalho (representação dos trabalhadores; plano de cargos, salários e benefícios; remuneração; escopo de práticas; composição das equipes).

\section{Contratação dos trabalhadores}

O Plano Municipal de Saúde (2010-2013) do primeiro mandato do governo Eduardo Paes (2009-2012) apresentou como objetivo 'desprecarizar’ os vínculos irregulares trabalhistas dos profissionais de saúde da SMS - contratos temporários, vínculos por bolsas, cooperativas de trabalho e triangulação por Organizações Não Governamentais (ONGs) ${ }^{25,38}$-, substituindo-os pela modalidade de contratação da CLT, a serem celebrados com as OSs, previstas na lei e em decretos municipais de 2009, as quais passaram a operar grande parte da Estratégia Saúde da Família (ESF) 21,22,25. A análise dos regulamentos de contratação de pessoal das OSs evidenciou que efetivamente foi aplicada a contratação por CLT ${ }^{\text {34-37. }}$.

A incorporação de profissionais na AP pelas OSs foi consolidada durante o segundo mandato do Eduardo Paes (2013-2016), conforme evidencia o documento do Plano Municipal de Saúde (2014-2017). Considerando todos os níveis de atenção à saúde, observa-se que foram eliminados os vínculos por cooperativa, que eram 932 em 2009; e incrementados os vínculos por CLT intermediados pelas OSs, que chegaram a 14.427 em 201226. Houve, também, uma diminuição do número de servidores públicos estatutários municipais, passando de 25.411, em 2009, para 24.534 , em $2012^{26}$. Cabe destacar que o vínculo celetista, quando comparado ao estatutário, é mais precário por não garantir, por exemplo, a estabilidade que assegura a permanência do trabalhador no serviço público.
Pouco antes do início do governo Eduardo Paes, em novembro de 2008, existiam apenas 128 equipes de saúde da família implantadas no município, e, ao final do seu segundo mandato, em novembro de 2016, foram alcançadas 951 equipes, o que possibilitou importante incremento de cobertura da AP no município ${ }^{39}$.

Vale lembrar que a CLT se tornou mais precária com a reforma trabalhista de 2017 , que, além de promover alterações nas formas de demissão, de estimular a contratação por terceirização e permitir o trabalho intermitente, afastando-se dos referenciais da proteção social do trabalho anteriores à reforma, reforçou também a primazia da negociação entre trabalhador e empregador com relação aos direitos já estabelecidos. Essas consequências foram efetivamente manifestadas durante o governo de Marcelo Crivella (mandato de 2017 a 2020).

A saúde do município do Rio de Janeiro, portanto, vem experimentando ao longo dos anos fragilidades nas modalidades de contratação, efeito da conjuntura mais ampla do neoliberalismo que afeta também os serviços públicos de saúde. Antes do governo Eduardo Paes, a fragilidade se expressava pelos contratos irregulares; durante o governo Eduardo Paes, houve a escolha política das Organizações Sociais, utilizando como modalidade de contratação a CLT - sem assegurar o cumprimento da totalidade dos direitos previstos; e no governo Marcelo Crivella, mantiveram-se as OSs e a contratação por CLT, introduzindo flexibilizações propiciadas pela reforma trabalhista e pela lei da terceirização de 2017.

Quanto às contribuições previdenciárias ou trabalhistas, todos os contratos de gestão destacam que as OSs são responsáveis por essas contribuições, tema que também aparece no decreto municipal. É previsto, adicionalmente, que a contratante (SMS) pode reter parcela de recurso da contratada (OS) no caso de não pagamento de obrigações previdenciárias/ trabalhistas por ela.

Entretanto, no governo Marcelo Crivella, a obrigatoriedade de pagamento dessas contribuições ficou comprometida em função do 
não repasse da totalidade de recursos financeiros da SMS para as OSs, comprometendo o pagamento de direitos trabalhistas dos profissionais de saúde, tais como salários e fundo de garantia, como veiculado em diferentes jornais da grande mídia ${ }^{40-43}$. Portanto, apesar do vínculo CLT, obrigações previdenciárias e trabalhistas básicas não foram cumpridas em sua totalidade.

A análise dos contratos de gestão identificou a possibilidade de subcontratação pela OS de serviços destinados à atividade-meio e à atividade-fim, e, nesses casos, o subcontratado deve ser responsável solidário com a contratada (OS) por obrigações, tais como as tributárias, trabalhistas e previdenciárias ${ }^{\mathbf{4 4}}$. Essa novidade foi identificada no contrato de gestão de 2019 da OS Ideias e está relacionada com as mudanças na regulação do trabalho, tendo em vista que, a partir da aprovação da lei da terceirização, em 2017, passou a ser permitida a terceirização de atividade-fim.

Portanto, por meio dos contratos de gestão com as OSs, abrem-se caminhos para relações de trabalho terceirizadas e quarteirizadas, possibilitando que os trabalhadores estejam vinculados a uma OS contratada ou a uma subcontratada da OS, contribuindo para aumentar o grau de incerteza quanto à garantia dos direitos trabalhistas.

No município do Rio, a empresa Doctor Vip Brasil atuou como quarteirizada, celebrando contrato com os trabalhadores pela natureza jurídica de Sociedade em Conta de Participação, caracterizada por uma sociedade criada entre duas ou mais pessoas para a realização de uma atividade comercial pré-determinada. A diferença dessa modalidade de contratação para a Pessoa Jurídica (PJ) é que na Sociedade em Conta de Participação não há necessidade de o profissional abrir firma ou possuir Cadastro Nacional da Pessoa Jurídica (CNPJ). Essas modalidades não preveem os direitos da CLT, não sendo possível obtê-los nem judicialmente ${ }^{45,46}$.

Outro ponto a ser destacado é a pluralidade nas modalidades de recrutamento e seleção para incorporação dos trabalhadores. Considerando os 4 regulamentos de contratação de pessoal analisados, há diferentes exigências nas etapas de seleção entre as OSs, Iabas, Gnosis e Viva Rio (quadro 2). A SPDM não faz referência às etapas de seleção no seu regulamento ${ }^{34-37}$.

Quadro 2. Etapas do processo seletivo das Organizações Sociais labas, Gnosis e Viva Rio

\begin{tabular}{lll}
\hline IABAS & VIVA RIO & GNOSIS \\
\hline Processo de seleção simplificado - & Processo seletivo interno ou externo & Pode conter as seguintes etapas ou \\
interno ou externo & - Análise do histórico profissional/ & outras mais apropriadas ao caso: \\
Pelo menos duas etapas, entre: & currículo & - Prova de conhecimentos especí- \\
- Prova objetiva e/ou redação; & Pode incluir também: & ficos; \\
- Análise do currículo e documentos & - Provas de conhecimentos gerais e/ & - Análise de currículo; \\
comprobatórios de requisitos míni- & ou específicos e/ou técnica com nota & - Avaliação psicológica: entrevistas, \\
mos; & mínima para aprovação; & aplicação de testes psicológicos e \\
- Duas entrevistas de avaliação (cará- & - Entrevistas (individual ou em gru- & dinâmicas de grupo. \\
ter eliminatório) & po); & Comprovação de especialização \\
& - Dinâmicas de grupo; & eventualmente exigida no edital de \\
Processo seletivo público & - Pesquisa cadastral no e-social (ape- & seleção \\
Pelo menos uma prova (objetiva ou & nas para processo seletivo externo) & \\
discursiva) & &
\end{tabular}

Fonte: Elaboração própria a partir do regulamento de contratação de pessoal do labas, regulamento interno para contratação de pessoal do Gnosis e regulamento de gestão de pessoas do Viva Rio ${ }^{34,35,37}$. 
Foi possível identificar diferentes etapas de seleção ao comparar dois editais de uma mesma OS. O edital 004/2015 exigiu as etapas de prova objetiva e entrevista técnica, enquanto o edital 11/2015 incluiu, além dessas etapas, a avaliação de títulos, sendo ambos editais da OS Iabas, do ano 2015 e para o cargo de enfermeiro ${ }^{47,48}$.

Existem, ainda, outras formas de divulgação de vagas menos reguladas que os editais, tais como os sites das OSs, site vagas.com. br e divulgação em redes sociais ${ }^{49-52}$. A OS IPCEP, por exemplo, criou o 'Canal do Médico' para atendimento por um número de WhatsApp e e-mail, para divulgação de vagas e para manter contato com os profissionais médicos ${ }^{53}$.

Essas diversidades observadas nos processos de recrutamento e seleção expressam a falta de normas mais gerais que orientem esses processos e garantam formas de incorporação dos trabalhadores menos desiguais e precárias.

\section{Gestão do trabalho}

Um primeiro aspecto a ser considerado sobre a gestão do trabalho é a representação de trabalhadores em instância deliberativa das OSs. A lei federal de qualificação das OSs não garante explicitamente a representação de trabalhadores no Conselho de Administração (CA), importante órgão de deliberação, deixando a cargo das legislações estaduais e municipais a definição mais específica ${ }^{10,11}$.

Diferentemente, a lei municipal do Rio de Janeiro define a representação de empregados das OSs nos CA em 10\% de seus integrantes ${ }^{21}$. A representação dos trabalhadores nos CA também está prevista em todos os estatutos das OSs analisadas, como exigido pela lei municipal citada ${ }^{30-33}$. A única exceção é a Fiotec, que, por sua condição de fundação de apoio a órgão da administração pública, não possui conselho administrativo, tendo sua configuração composta por conselho curador, conselho fiscal e diretoria executiva, para os quais não há previsão de representação dos trabalhadores da $\mathrm{OS}^{29}$.
Outro aspecto a ser ressaltado refere-se à previsão de plano de cargos, salários e benefícios para os trabalhadores das OSs. A lei federal e a lei municipal do Rio de Janeiro de qualificação das OSs exigem que o CA aprove um regulamento contendo esse plano ${ }^{11,21}$. Igualmente, todos os estatutos analisados das OSs, com exceção da Fiotec, que não possui $\mathrm{CA}$, preveem essa atribuição para os Conselhos ${ }^{29-33}$. Apesar da previsão do plano de cargos, salários e benefícios, não há exigência de criação de um plano de carreira que possibilite a progressão do trabalhador. Esse aspecto aponta para a falta de perspectiva de ascensão profissional e insegurança quanto ao futuro. Essa situação pode favorecer o desligamento e a rotatividade de trabalhadores, o que é prejudicial para a continuidade dos serviços.

Sobre a remuneração paga aos trabalhadores, vale destacar que foram observadas diferenças ao comparar os valores contidos nos editais de seleção das OSs. Na SPDM, por exemplo, três editais de 2017 para seleção de Agentes Comunitários de Saúde (ACS) definiram diferentes valores: $R \$ 1.155,50, R \$ 1.213,28$ e $R \$$ $1.262,20$, além de incluírem vale-alimentação e vale-refeição em todos os editais ${ }^{54-56}$. Uma diferença no salário de R $\$ 106,07$, considerando um salário pouco maior que mil reais, é uma diferença importante (cerca de 10\%). Essa condição evidencia a assimetria que existe entre profissionais contratados por uma mesma OS e que exercem a mesma função laboral.

Além disso, a OS IPCEP, nos editais de 2019, durante o governo Crivella, reduziu as remunerações de algumas categorias profissionais quando comparadas aos valores pagos por outras OSs no ano anterior. Para os enfermeiros, os valores pagos em 2018 pelas OSs Gnosis e Iabas eram de, respectivamente, R\$ 5.976,66, acrescidos de insalubridade e possível

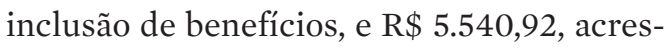
cidos de vale-transporte, seguro de vida em grupo e vale-alimentação ou refeição. Em 2019, o valor oferecido em três editais do IPCEP para essa mesma categoria era de $\mathrm{R} \$ 4.263,00$, somado apenas o adicional de insalubridade $\mathrm{R} \$ 199,60^{57-61}$. 
Destacam-se, também, aspectos sobre o escopo de práticas dos ACS. A PNAB 2017 ampliou o rol de atividades a serem realizadas pelos ACS, os quais passaram a aferir pressão arterial, realizar medição de glicemia capilar, aferir temperatura axilar, realizar técnicas limpas de curativo, entre outros, desde que assistidos por um profissional de saúde de nível superior. A realização de novas atividades compromete a execução de ações mais abrangentes (exemplo: ações educativas e de promoção da saúde), distanciando os agentes de suas atividades originais no trabalho comunitário ${ }^{23,62-65}$.

Durante o período estudado, ocorreram, também, mudanças na composição das equipes da atenção básica. A PNAB 2017 (Portaria no 2.436/2017) possibilitou a diminuição do quantitativo de ACS por equipe se comparada à PNAB anterior (Portaria $n^{\circ} 2.488 / 2011$ ). Além disso, a PNAB 2017 reconheceu e concedeu incentivo financeiro às equipes tradicionais de atenção básica (incentivo antes destinado somente às equipes de ESF), nas quais não há exigência de ACS na equipe mínima ${ }^{23,66}$. Assim, diante de um contexto de austeridade e subfinanciamento do SUS, incentivou-se a constituição de equipes tradicionais, contribuindo para a alteração dos processos de trabalho, redução do número de trabalhadores e consequente aumento da carga de trabalho.

Essas mudanças no regramento da PNAB em nível federal influenciaram o município do Rio de Janeiro durante o governo Marcelo Crivella. No final de outubro de 2018, no documento 'Reorganização dos Serviços de Atenção Primária à Saúde', foi proposta a extinção de 184 equipes de saúde da família e 55 equipes de saúde bucal, com corte total de cerca de 1.400 postos de trabalho, contrariando as metas de aumento das equipes apresentadas no Plano Municipal de Saúde (2018-2021), que propunha passar de 1.294 equipes de saúde da família e de saúde bucal, em 2018, para 1.314, 1.334 e 1.354 equipes, respectivamente, em 2019, 2020 e 202127,28. Sublinha-se que, em novembro de 2019, o número de equipes de saúde da família implantadas caiu para 923 equipes, expressando, de forma contrária ao definido no Plano Municipal, uma importante retração da $\mathrm{ESF}^{39}$. Essa diminuição foi facilitada pelas contratações via CLT por OS, mais vulneráveis às mudanças de governo e, também, pelas alterações promovidas pela $\mathrm{PNAB}$ e pela reforma trabalhista, aprovadas em 2017.

Outra alteração na composição das equipes foi apresentada na proposta de reorganização da AP no Rio de Janeiro, em 2018, estabelecendo que as equipes deveriam ser diferentes em razão do Índice de Desenvolvimento Social (IDS). Regiões com IDS mais alto teriam uma equipe composta por ao menos um médico, enfermeiro e técnico de enfermagem, sem prever a incorporação obrigatória de ACS, e tendo uma população adscrita de até 16.000 habitantes ${ }^{\mathbf{2 8}}$. Usar esse indicador para definição do número e da composição de equipes em regiões que convivem com IDS altos e baixos pode distorcer a necessidade de equipes, reduzindo a atenção prestada e ocasionando sobrecarga de trabalho às equipes.

\section{Considerações finais}

As relações de trabalho no SUS e na AP se relacionam diretamente com a conjuntura política e econômica em que se inserem, sendo afetadas pelo contexto neoliberal e de reforma do Estado. O modelo jurídico das OSs foi criado no contexto de reforma do Estado, com regras mais próximas do setor privado e maior flexibilização das relações de trabalho.

O estudo da trajetória da política de AP no período considerado permitiu reconstruir argumentos, dimensões legislativas e regulamentares, bem com as inflexões e evolução da política.

As mudanças nos regramentos em nível federal, com a reforma trabalhista de 2017, enfraqueceram a contratação coletiva do trabalho, aumentando a assimetria de poder dos trabalhadores frente aos interesses patronais, agravadas com a supressão da gratuidade da Justiça do Trabalho e pela liberação do 
negociado sobre o legislado. Adicionalmente, as mudanças na PNAB 2017 também contribuíram para redução do número de equipes de saúde da família e de trabalhadores na AP, principalmente dos ACS, gerando consequências para o trabalho.

A opção pela contratação de pessoal por meio das OSs no governo de Eduardo Paes, embora com a pretensão de 'desprecarizar' e regularizar as relações de trabalho, e apesar de ampliar a cobertura da AP à população do município do Rio de Janeiro, contribuiu para reduzir o escopo dos direitos trabalhistas dos profissionais contratados pelas OSs, ao abrir caminho para uma formalização celetista precarizada.

Já o governo de Marcelo Crivella não assume o custo político de romper com o modelo de atenção que assegurou a ampliação da cobertura do governo anterior, porém, com o estrangulamento de recursos repassados de forma não mais regular para as OSs, acentua as fragilidades do modelo, principalmente com relação ao trabalho. Nesse governo, a incerteza ou a não garantia de direitos trabalhistas se expressaram de forma mais intensa, com a quarteirização, a redução na remuneração dos trabalhadores e o não cumprimento de obrigações trabalhistas e previdenciárias.

A proposta apresentada pelo documento da reorganização da AP do município, com redução de custos, mudanças na tipologia das equipes e redução de trabalhadores e equipes, foi condizente com as mudanças das regras em nível federal, seja a mudança a partir da EC 95, de 2016, que trouxe constrangimentos financeiros ao SUS, seja a mudança a partir da PNAB 2017, que permitiu a diminuição de ACS e formatos de equipes distantes do modelo das equipes de saúde da família.
O poder discricionário das OSs reflete pluralidade das regras no que se refere às modalidades de recrutamento e seleção, o que resulta em uma situação de precarização diante das incertezas geradas para os profissionais. Também são identificadas: fragilidade, no nível federal, no que se refere à garantia de representação de trabalhadores em órgão deliberativo da OS, e alterações, no que se refere às atribuições dos ACS, o que coloca em questão o modelo de atenção à saúde, distanciando os agentes de suas ações de promoção da saúde no território.

O contexto de crise da AP no município do Rio de Janeiro trouxe preocupações quanto à sustentabilidade dos serviços baseados no modelo jurídico das OSs. A rápida expansão da $\mathrm{AP}$ ocorreu às custas da precarização nas relações de trabalho, concretizada na terceirização e quarteirização, no atraso ou não pagamento de direitos trabalhistas, na sobrecarga de trabalho, na demissão de trabalhadores, entre outros aspectos explicitados. Nesse sentido, as regras do jogo, contidas nas normativas analisadas, são capazes de expressar diferentes modos da precarização do trabalho presentes na AP do município.

A ampliação do acesso desejável, por si só, não assegura os atributos necessários à qualidade do cuidado ofertado pela AP à população - vínculo, integralidade, longitudinalidade do cuidado etc., que requerem trabalhadores qualificados e com condições dignas de trabalho.

\section{Colaboradoras}

Fonseca JM (0000-0002-3339-7193)*, Lima SML (0000-0003-1450-0498)* e Teixeira M (0000-0002-9502-0789)* contribuíram igualmente para a elaboração do manuscrito. 


\section{Referências}

1. Lazzareschi N. Flexibilização, desregulamentação e precarização das relações de trabalho: uma distinção necessária. Revista Labor. 2015; (13)63-82.

2. Kalleberg AL. O crescimento do trabalho precário: um desafio global. Rev. Bras. Ciênc. Sociais. 2009; 24(69):21-30.

3. Filgueiras VA, Cavalcante, SM. Terceirização: debate conceitual e conjuntura política. Revista da ABET. 2015; 14(1):15-36.

4. Siqueira Neto JF. Flexibilização, desregulamentação e o direito do trabalho no Brasil. In: Oliveira CAB, Mattoso JEL, editores. Crise e trabalho no Brasil: modernidade ou volta ao passado? São Paulo: Scritta; 1996. p. 327-344.

5. Sanches AT. Terceirização e terceirizados no setor bancário: relações de emprego, condições de trabalho e ação sindical. [dissertação]. São Paulo: Pontifícia Universidade Católica de São Paulo; 2006. 156 p. [acesso em 2019 jul 18]. Disponível em: https:// tede2.pucsp.br/bitstream/handle/3777/1/Ana\%20 Tercia\%20Sanches.pdf.

6. Antunes R, Druck G. A terceirização sem limites: a precarização do trabalho como regra. O social em quest. 2015; (34):19-40.

7. Antunes R. Aumento da miséria extrema, informalidade e desigualdade marcam os dois anos da Reforma Trabalhista. Jornal da Unicamp. 2019. [acesso em 2019 set 12]. Disponível em: https://www.unicamp.br/unicamp/ju/ noticias/2019/11/11/aumento-da-miseria-extrema-informalidade-e-desigualdade-marcam-os-dois-anos.

8. Contreiras H, Matta GC. Privatização da gestão do sistema municipal de saúde por meio de Organizações Sociais na cidade de São Paulo, Brasil: caracterização e análise da regulação. Cad. Saúde Pública 2015; 31(2):285-297.

9. Costa e Silva V, Escoval A, Hortale VA. Contratualização na Atenção Primária à Saúde: a experiência de
Portugal e Brasil. Ciên. Saúde Colet. 2014; 19(8):35933604.

10. Teixeira M, Matta GC, Silva Junior AG. Modelos de gestão na atenção primária à saúde: uma análise crítica sobre gestão do trabalho e produção em saúde. In: Mendonça MHM, Matta GC, Gondim R, et al. Atenção primária à saúde no Brasil: conceitos, práticas e pesquisa. Rio de Janeiro: Fiocruz; 2018. p. 117-142.

11. Brasil. Lei n ${ }^{0} 9.637$, de 15 de maio de 1998. Dispõe sobre a qualificação de entidades como Organizações Sociais, a criação do Programa Nacional de Publicização, a extinção dos órgãos e entidades que menciona e a absorção de suas atividades por organizações sociais, e dá outras providências. Diário Oficial da União. 16 Maio 1998.

12. Pochmann M. A uberização leva à intensificação do trabalho e da competição entre os trabalhadores. Revista POLI - Saúde, edu. Trab. 2016; IX(48):16-19.

13. Krein JD. O desmonte dos direitos, as novas configurações do trabalho e o esvaziamento da ação coletiva: consequências da reforma trabalhista. Tempo Social. 2018; 30(1):77-104.

14. Bahia L. Trinta anos de Sistema Único de Saúde (SUS): uma transição necessária, mas insuficiente. Cad. Saúde Pública. 2018; 34(7):1-16.

15. Brasil. Lei $n^{\circ} 13.467$, de 13 de julho de 2017. Altera a Consolidação das Leis do Trabalho (CLT), aprovada pelo Decreto-Lei ${ }^{\circ} 5.452$, de $1^{\circ}$ de maio de 1943 , e as Leis $\mathrm{n}^{0}$ 6.019, de 3 de janeiro de 1974, 8.036, de 11 de maio de 1990, e 8.212, de 24 de julho de 1991, a fim de adequar a legislação às novas relações de trabalho. Diário Oficial da União. 14 Jul 2017.

16. Brasil. Lei $\mathrm{n}^{\circ} 13.429$, de 31 de março de 2017 . Altera dispositivos da Lei ${ }^{\circ} 6.019$, de 3 de janeiro de 1974, que dispõe sobre o trabalho temporário nas empresas urbanas e dá outras providências; e dispõe sobre as relações de trabalho na empresa de prestação de serviços a terceiros. Diário Oficial da União. 31 Mar 2017. 
17. Ramos ALP, De Seta MH, Andrade CLT. Terceirização e Desempenho da Atenção Primária à Saúde nas Capitais Brasileiras. In: Sá MC, Tavares MFL, De Seta MH. Organização do cuidado e práticas em saúde: abordagens, pesquisas e experiências de ensino. Rio de Janeiro: Fiocruz; 2018. p. 295-357.

18. Rio de Janeiro. Organizações Sociais - Saúde da Família - Contratos de Gestão. 2019. [acesso em 2020 mar 20]. Disponível em: http://www.rio.rj.gov.br/ $\mathrm{web} / \mathrm{sms} /$ exibeconteudo?id=2247880.

19. Lima LD, Machado CV, Gerassi CD. O neo-institucionalismo e a análise de políticas de saúde: contribuições para uma reflexão crítica. In: Mattos RA, Baptista TWF. Caminhos para análise das políticas de saúde. Porto Alegre: Rede Unida; 2015. p. 181-219.

20. North D. The new institucional economics and development. Economic Working Paper Archive. 1993; 1-8.

21. Rio de Janeiro. Lei ${ }^{\circ} 5.026$ de 19 de maio de 2009. Dispõe sobre a qualificação de entidades como Organizações Sociais e dá outras providências. Diário Oficial do Município do Rio de Janeiro. 20 Maio 2009.

22. Rio de Janeiro. Decreto $\mathrm{n}^{\mathrm{o}} 30.780$, de 2 de junho de 2009. Regulamenta a lei municipal no 5.026 , de 19 de maio de 2009, que dispõe sobre a qualificação de entidades como Organizações Sociais e dá outras providências. Diário Oficial do Município do Rio de Janeiro. 3 Jun 2009.

23. Brasil. Portaria ${ }^{\circ}$ 2.436, de 21 de setembro de 2017. Aprova a Política Nacional de Atenção Básica, estabelecendo a revisão de diretrizes e normas para a organização da Atenção Básica, para a Estratégia Saúde da Família (ESF) e o Programa de Agentes Comunitários de Saúde (PACS). Diário Oficial da União. 22 Set 2017.

24. Fundação Oswaldo Cruz, Escola Nacional de Saúde Pública Sergio Arouca. Seção disponibiliza documentos sobre 'reorganização' da ESF no Rio de Janeiro. 2018. [acesso em 2021 jul 22]. Disponível em: http:// www.ensp.fiocruz.br/portal-ensp/informe/site/materia/detalhe/45172.
25. Rio de Janeiro. Secretaria Municipal de Saúde e Defesa Civil. Plano Municipal de Saúde do Rio de Janeiro 2010-2013. 2009. [acesso em 2019 out 24]. Disponível em: http://www.rio.rj.gov.br/dlstatic/10112/3700816/4130215/PLANOMUNICIPALDESAUDE20102013.pdf.

26. Rio de Janeiro. Secretaria Municipal de Saúde. Plano Municipal de Saúde do Rio de Janeiro 2014-2017. 2013. [acesso em 2019 out 24]. Disponível em: http:// www.rio.rj.gov.br/dlstatic/10112/3700816/4128745/ PMS_20142017.pdf.

27. Rio de Janeiro. Secretaria Municipal de Saúde do Rio de Janeiro. Plano Municipal de Saúde 2018-2021. 2018. [acesso em 2019 out 24]. Disponível em: http:// www.rio.rj.gov.br/dlstatic/10112/7677780/4225104/ PMS2018_VersaoPreliminar.pdf.

28. Rio de Janeiro. Secretária Municipal de Saúde, Subsecretaria de Atenção Primária. Reorganização dos Serviços de Atenção Primária à Saúde. Rio de Janeiro: SUBPAV; 2018.

29. Fundação para o Desenvolvimento Científico e Tecnológico em Saúde. Alteração de Estatuto - FIOTEC. 2002. [acesso em 2019 ago 6]. Disponível em: http:// www.fiotec.fiocruz.br/documentacao/104-alteracao-do-estatuto-pt/file.

30. Instituto de Atenção Básica e Avançada à Saúde. Estatuto - $24^{\text {a }}$ alteração consolidada. 2017. [acesso em 2019 ago 6]. Disponível em: http://iabas.org.br/?page_id=128.

31. Instituto Gnosis. Estatuto Social do Instituto Gnosis $-5^{\text {a }}$ alteração consolidada. 2017. [acesso em 2019 ago 6]. Disponível em: https://www.institutognosis. org.br/estatuto-social.

32. Associação Paulista Para o Desenvolvimento da Medicina. Estatuto Social - Associação Paulista para o Desenvolvimento da Medicina. 2014. [acesso em 2019 ago 6]. Disponível em: https://www.spdm.org. br/images/stories/pdf/Estatuto_SPDM_2015.pdf.

33. Viva Rio. Estatuto Social da Associação de Fins Não Econômicos Denominada Viva Rio 2017. 2017. [aces- 
so em 2019 ago 6]. Disponível em: http://vivario.org. br/regulamentos/.

34. Instituto de Atenção Básica e Avançada à Saúde. Regulamento de contratação de pessoal. [acesso em 2019 ago 21]. Disponível em: http://iabas.org.br/wp- content/uploads/2017/07/Regulamento_Interno_de_ Contratacao_de_Pessoal-revll.pdf.

35. Instituto Gnosis. Regulamento interno para contratação de pessoal - Dispõe sobre os procedimentos internos necessários para contratação de pessoal para o Instituto Gnosis. [acesso em 2019 ago 21]. Disponível em: https://www.institutognosis.org.br/copia-regimento-interno.

36. Associação Paulista para o Desenvolvimento da Medicina. Regulamento Interno - Departamento de Recursos Humanos. [acesso em 2019 ago 21]. Disponível em: https://www.spdm.org.br/flip/manual_funcionario/manual_funcionario.pdf.

37. Viva Rio. Regulamento de gestão de pessoas. 2019. [acesso em 2019 ago 21]. Disponível em: http://vivario.org.br/regulamentos/.

38. Teixeira M, Oliveira RG, Arantes RF. Mudanças nas políticas do trabalho e da educação em saúde no governo Lula. In: Machado CV, Baptista TWF, Lima LD. Políticas de Saúde no Brasil: continuidades e mudanças. Rio de Janeiro: Editora Fiocruz; 2012. p. 197-225.

39. Brasil. E-Gestor Atenção Básica. Histórico do quantitativo de equipes e serviços custeados na Atenção Primária à Saúde. Brasília, DF: Ministério da Saúde; 2019. [acesso em 2019 dez 18]. Disponível em: https:// egestorab.saude.gov.br/paginas/acessoPublico/relatorios/relHistoricoPagamentoEsf.xhtml.

40. Carneiro CCG, Martins MIC. Novos modelos de gestão do trabalho no setor público de saúde e o trabalho do agente comunitário de saúde. Rev. Trab. Edu. Saúde. 2015; 13(1):45-66.

41. Lettiere G, Bianchi P. Rio: rede municipal de saúde tem salários atrasados e falta de remédio. UOL. 2017 ago 31. [acesso em 2019 dez 12]. Disponível em: ht- tps://noticias.uol.com.br/saude/ultimas-noticias/redacao/2017/08/31/sem-dinheiro-da-prefeitura-oss-atrasam-salarios-e-falta-remedio-e-comida.htm.

42. Rodrigues M. TRT ordena bloqueio de R $\$ 300$ milhões após Prefeitura do Rio apresentar contas. G1. $2019 \mathrm{dez}$ 12. [acesso em 2019 dez 12]. Disponível em: https:// gl.globo.com/rj/rio-de-janeiro/noticia/2019/12/12/ trt-expede-mandado-para-bloquear-r-300-milhoes-apos-prefeitura-do-rio-apresentar-contas.ghtml.

43. Seara B, Macedo A. Prefeitura do Rio tem R \$ 325 milhões arrestados para pagar salários da Saúde. Jornal Extra. 2019 nov 26. [acesso em 2019 dez 12]. Disponível em: https://extra.globo.com/noticias/extra-extra/ prefeitura-do-rio-tem-325-milhoes-arrestados-para-pagar-salarios-da-saude-rvl-1-24102276.html.

44. Instituto de Desenvolvimento Institucional e Ação Social. Contrato de gestão $\mathrm{n}^{\circ} 025 / 2019$. 2019. [acesso em 2019 nov 28]. Disponível em: http://www. rio.rj.gov.br/dlstatic/10112/9016020/4261306/ CG025_2019CAP1.0.pdf.

45. Doctor Vip Brasil. Trabalhe conosco. 2019. [acesso em 2019 dez 16]. Disponível em: https://www.doctorvipbrasil.net.br.

46. Guimarães A, Prado A, Bassan P. Documentos mostram ligações entre família de Crivella e fornecedores da área da saúde no Rio. G1. 2020 maio 25. [acesso em 2020 maio 26]. Disponível em: https://gl.globo.com/ rj/rio-de-janeiro/noticia/2020/05/25/documentos-mostram-ligacoes-entre-a-familia-de-crivella-e-fornecedores-da-area-da-saude-no-rio.ghtml.

47. Instituto de Atenção Básica e Avançada à Saúde. Edital 004/2015. 2015 [acesso em 2019 ago 18]. Disponível em: https://jcconcursos.uol.com.br/media/uploads/anexos/2015/rj_iabas_3_ed_1795.pdf.

48. Instituto de Atenção Básica e Avançada à Saúde. Edital 11/2015. 2015. [acesso em 2019 ago 18]. Disponível em: https://arquivo.pciconcursos.com.br/iabas-rj-abre-cinco-processos-seletivos-com-vagas-imediatas-e-cadastro-reserva/1331120/56c434ad7e/edital de_abertura_n_11_2015.pdf. 
49. Instituto Gnosis. Página Facebook. 2019. [acesso em 2019 dez 3]. Disponível em: https://www.facebook. com/institutognosis/.

50. Instituto de Desenvolvimento Institucional e Ação Social. Abertura de processo seletivo. 2019. [acesso em 2019 dez 3]. Disponível em: http://ideiasrj.org.br/ vagas-abertas/.

51. Associação Paulista Para o Desenvolvimento da Medicina. Perfil Spdmpais. Instagram: @Spdmpais. 2019. [acesso em 2019 dez 3]. Disponível em: https://www. instagram.com/spdmpais/.

52. Vagas. Vaga enfermeiro - Viva Rio. 2016. [acesso em 2019 dez 3]. Disponível em: www.vagas.com/ v1420728.

53. Instituto de Psicologia clínica Educacional e Profissional. Página IPCEP. Facebook: @IPCEP. 2019. [acesso em 2019 dez 11]. Disponível em: https://www.facebook.com/IPCEP/.

54. Associação Paulista Para o Desenvolvimento da Medicina. Edital 01/2017 da AP1.0. 2017. [acesso em 2019 ago 18]. Disponível em: http://www.spdmpais.org.br/ images/pdf/rj/Edital_01_2017_ESTÁCIO_SÁ.pdf.

55. Associação Paulista Para o Desenvolvimento da Medicina. Edital 02/2017 da AP3.2. [acesso em 2019 ago 18]. Disponível em: http://www.spdmpais.org.br/images/pdf/rj/Edital_02-2017.pdf.

56. Associação Paulista para o Desenvolvimento da Medicina. Edital 05/2017. [acesso em 2019 ago 18]. Disponível em: http://www.spdmpais.org.br/images/ pdf/rj/Edital_05-2017.pdf.

57. Instituto de Atenção Básica e Avançada à Saúde. Edital 03/2018. [acesso em 2019 ago 18]. Disponível em: https://www.ibade.org.br/Cms_Data/Contents/SistemaConcursoIBADE/Media/IABASESF2018/Edital/EDITAL_ESF_PARA_DIVULGACAO_180418. pdf. Acesso em: 18 ago. 2019.

58. Instituto Gnosis. Edital 04/2018. [acesso em 2019 ago 18]. Disponível em: https://0e042c68-bd6b-4653- b8c4-08587cb70e7c.filesusr.com/ugd/d3df7f_4121 6b7c48fa4cc19198a78fa899d504.pdf.

59. Instituto de Psicologia clínica Educacional e Profissional. Edital 09/2019. [acesso em 2019 ago 18]. Disponível em: http://ipcep.org.br/novo/?page_id=2598.

60. Instituto de Psicologia clínica Educacional e Profissional. Edital 10/2019. [acesso em 2019 ago 18]. Disponível em: http://ipcep.org.br/novo/?page_id=2598.

61. Instituto de Psicologia clínica Educacional e Profissional. Edital 68/2019. [acesso em 2019 ago 18]. Disponível em: http://ipcep.org.br/novo/?page_id=2598.

62. Morosini MV, Fonseca AF. Os agentes comunitários na Atenção Primária à Saúde no Brasil: inventário de conquistas e desafios. Saúde debate. 2018; 42(1):261274.

63. Melo EA, Mendonça MHM, Oliveira JR, et al. Mudanças na Política Nacional de Atenção Básica: entre retrocessos e desafios. Saúde debate. 2018; 42(esp1):3851.

64. Morosini MVGC, Fonseca AF. Revisão da Política Nacional de Atenção Básica numa hora dessas? Cad. Saúde Pública. 2017; 33(1):1-4.

65. Morosini MVGC, Fonseca AF, Lima LD. Política Nacional de Atenção Básica 2017: retrocessos e riscos para o Sistema Único de Saúde. Saúde debate. 2018; 42(116):11-24

66. Brasil. Portaria n ${ }^{\circ} 2.488$, de 21 de outubro de 2011. Aprova a Política Nacional de Atenção Básica, estabelecendo a revisão de diretrizes e normas para a organização da Atenção Básica, para a Estratégia Saúde da Família (ESF) e o Programa de Agentes Comunitários de Saúde (PACS). Diário Oficial da União. 22 Out 2011.

\footnotetext{
Recebido em 12/11/2020

Aprovado em 31/05/2021

Conflito de interesses: inexistente

Suporte financeiro: não houve
} 